\title{
The Role of Pedobarography and Therapeutic Padding in the Management of Hyperkeratosis due to Mechanical Stress
}

\author{
Anca Chiriac 1,2,3, Cristian Podoleanu4 ${ }^{4}$, Adrian Năznean 5 , Simona Stolnicu6 \\ 1 Department of Dermato-Physiology, Apollonia University, Iași, Romania \\ 2 Department of Dermatology, Nicolina Medical Center, Iași, Romania \\ 3 "P. Poni” Institute of Macromolecular Chemistry, Apollonia University, lași, Romania \\ ${ }^{4}$ Department of Cardiology, University of Medicine, Pharmacy, Science and Technology, Târgu Mureș, Romania \\ 5 Department of Foreign Languages, University of Medicine, Pharmacy, Science and Technology, Târgu Mureș, Romania \\ ${ }^{6}$ Department of Pathology, University of Medicine, Pharmacy, Science and Technology, Târgu Mureș, Romania
}

\section{CORRESPONDENCE}

\section{Adrian Năznean}

Str. Gheorghe Marinescu nr. 38

540139 Târgu Mureș, Romania

Tel: +40 265215551

E-mail: adinaznean@yahoo.com

\section{ARTICLE HISTORY}

Received: February 3, 2019

Accepted: April 24, 2019
Anca Chiriac • Str. Hatman Sendrea nr. 2, 700613 lași, Romania. Tel: +40332808703

Cristian Podoleanu • Str. Gheorghe Marinescu nr. 38 540139 Târgu Mureș, Romania. Tel: +40 0265215551 Simona Stolnicu • Str. Gheorghe Marinescu nr. 38 540139 Târgu Mureș, Romania. Tel: +40 0265215551

\begin{abstract}
Hyperkeratotic lesions result from continuous mechanical action on the skin forming a callus or a corn. The accumulation of horny layers will increase pressure, creating a vicious cycle. We present a new approach based on relieving pressure or friction, strictly based on the results of pedography (pedobarography).
\end{abstract}

Keywords: skin, mechanical hyperkeratosis, therapy, pedography

\section{BACKGROUND}

Various mechanical factors may induce distinctive skin changes. Hyperkeratotic lesions do not correspond to a skin disease; they are the result of a continuous mechanical action on the skin. The body reacts by hyperkeratosis, trying to protect the skin by forming a callus or a corn. However, the accumulation of horny layers will increase the pressure, creating a vicious cycle.

It is estimated that approximately $20 \%$ of the general population suffers from hyperkeratotic lesions induced by mechanical trauma, which are distributed mostly on the foot and toes, especially in women and the elderly. ${ }^{1}$

A callus is a non-penetrating circumscribed hyperkeratosis induced by pressure, most frequently on the palms and soles, over the bony prominences of the joints. It is a painful local thickening of the skin as a result of a mechanical injury, with acute evolution, caused by intermittent pressure. Some sportsmen may develop callosities, as well as people with specific occupations, as stigmata of their profession (violin players for example).2,3 

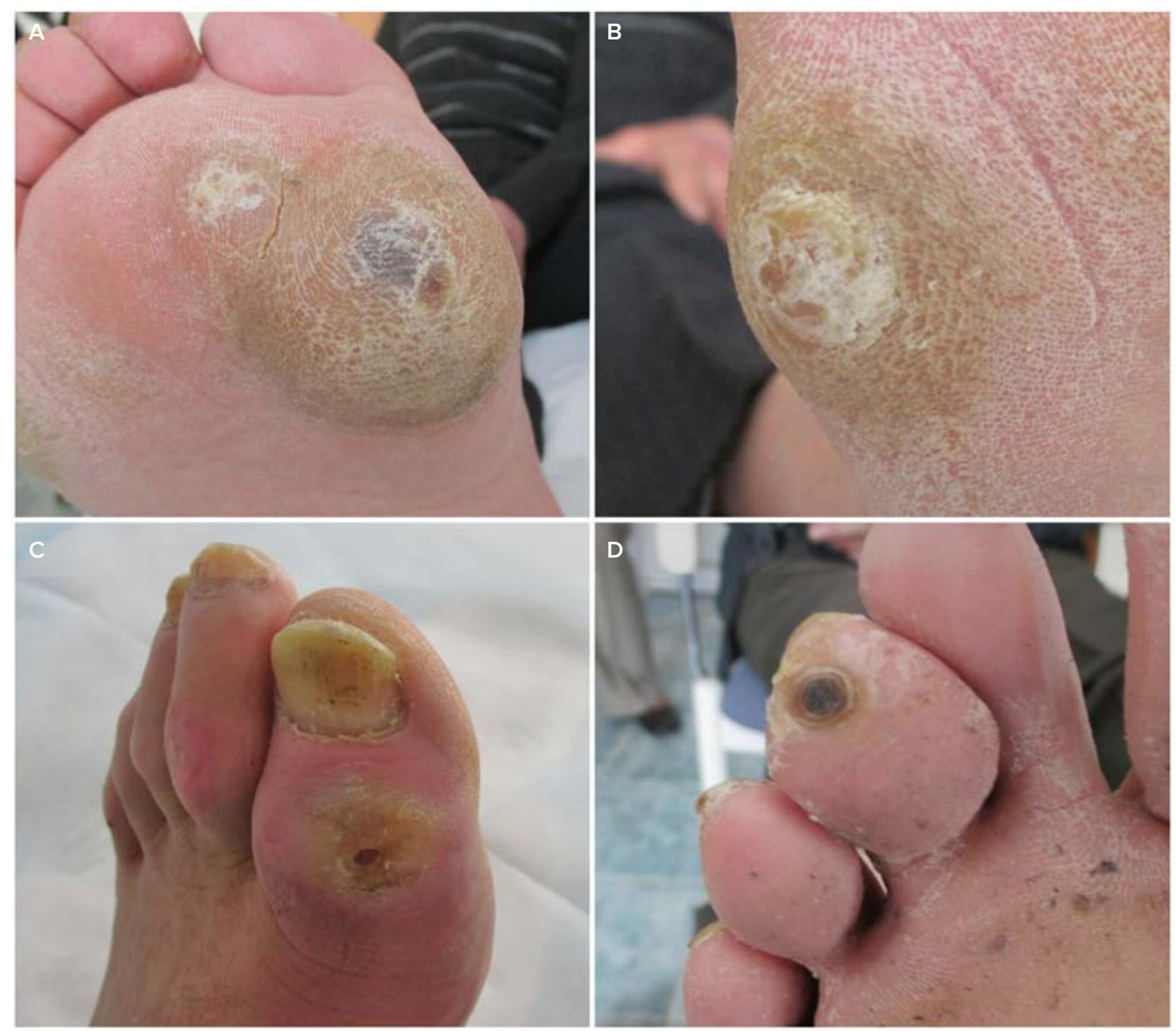

FIGURE 1. Bilateral plantar clavus of the left (A) and right (B) foot; hard corn on the dorsal aspect of toe I, II (C); Corn on the plantar face of toe III (D).

Ill-fitting shoes, rheumatic diseases, orthopedic anomalies (exostoses) of the foot are the main causes of callosities. Plantar keratosis and metatarsal head callus are often associated with metatarsophalangeal dislocation in rheumatoid arthritis.

A callus must be differentiated from a clavus (corn) for being more diffuse and without a penetrating central core. A clavus, in contrast, is a circumscribed conical thickening of the skin, penetrating the subjacent structure. Three types of clavuses have been described: hard corn (heloma durum) on the dorsa of the toes or soles; soft corn (heloma mole) between the toes; and seed corn (heloma millare). Extreme pain caused by a clavus is explained by its penetrating effect, by irritating the sensory nerves from the papillary dermis, and by mechanical trauma (Figure $1 \mathrm{~A}$, B, C, D).

The soft interdigital clavus occurs especially in the fourth interdigital space of the foot.

Plantar callosities are a common cause of pain in the forefoot and the main cause of alterations in plantar pressure.

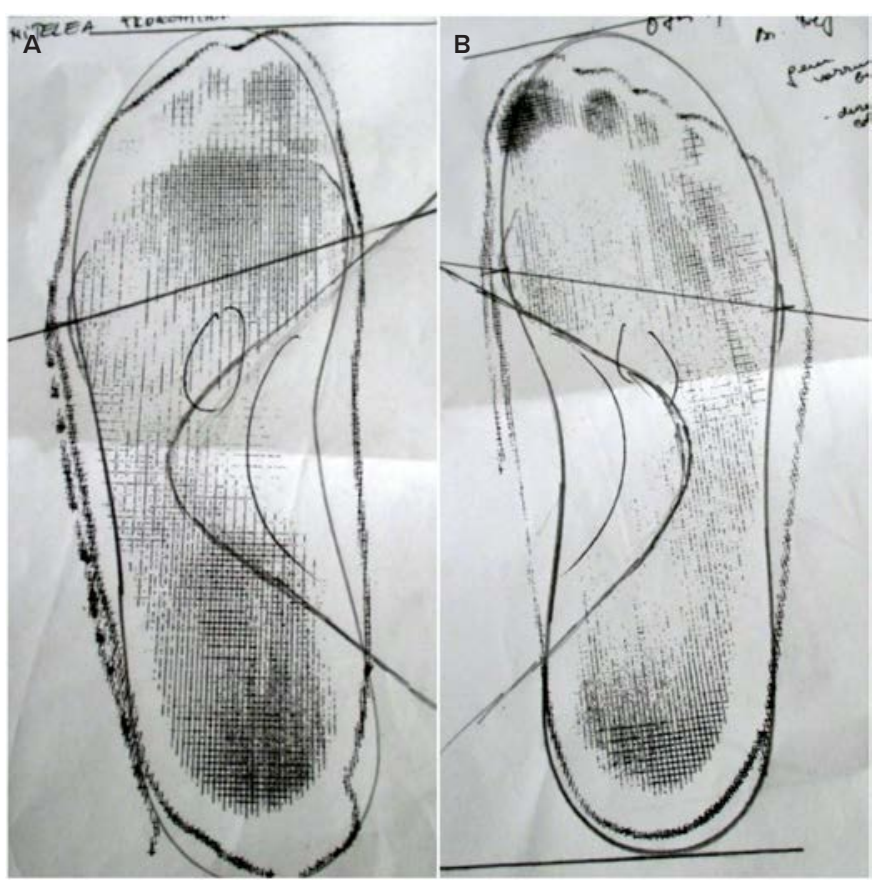

FIGURE 2. Personalized pedography showing the pressure points and orthopedic anomalies in the left (A) and right (B) foot 

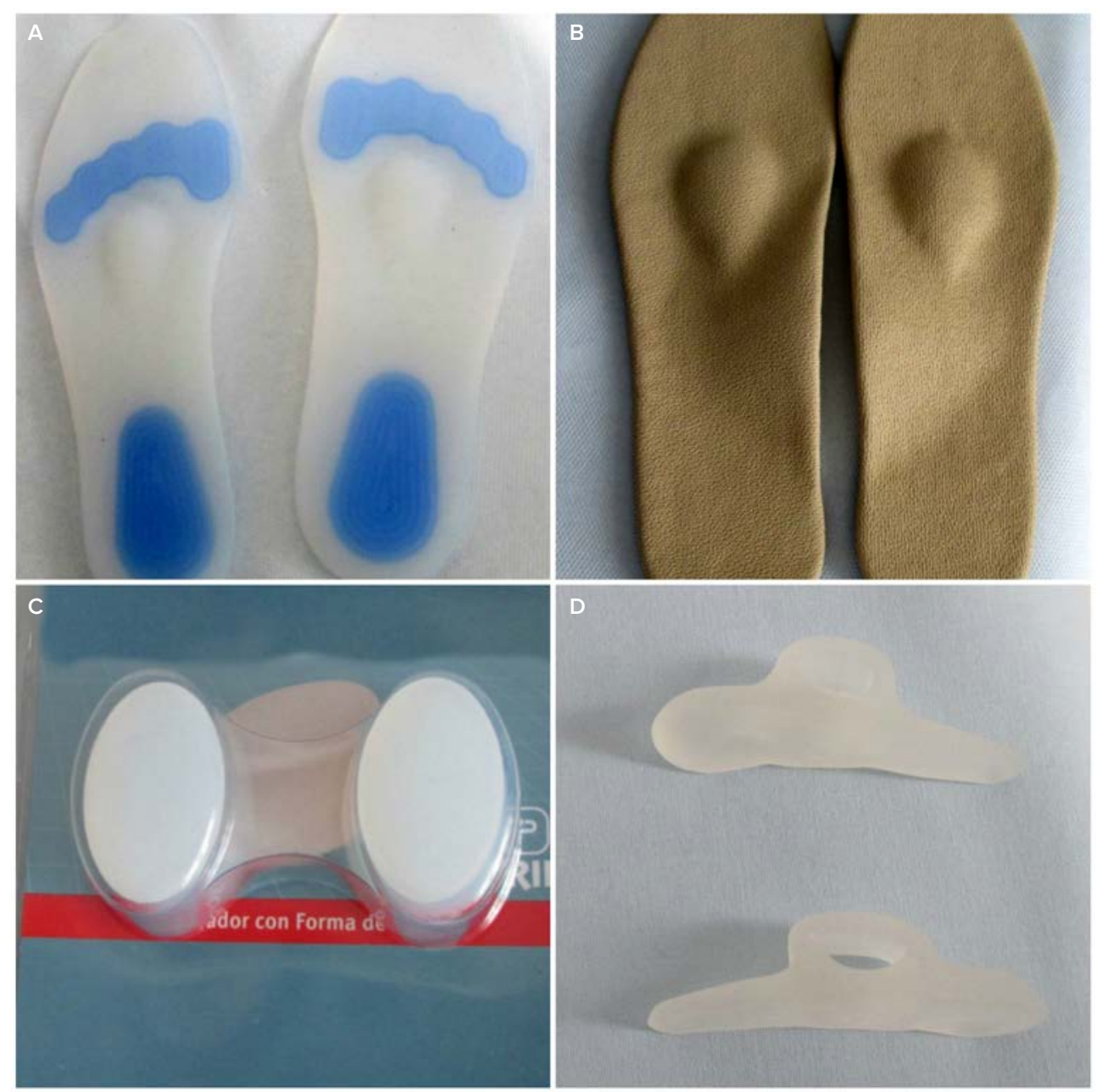

FIGURE 3. Different orthopedic corrections correlated to underlying foot deformity (A, B); silicone toe separators (spreaders) (C); silicon toe-protector and corrective pads (D)

\section{THERAPEUTIC MEASURES FOR HYPERKERATOTIC DERMATOSES}

The treatment of hyperkeratotic dermatoses is difficult and relies on various methods. Emollients, warm saline water, and pumice stone are used to remove the thickened skin in minor forms, in the absence of diabetes mellitus or foot infection.

Due to its mechanism of producing the lesions, plantar callosities may disappear when the offending mechanical pressure is removed. The most practiced methods of treatment of callosities and clavus are based nowadays on mechanical debridement with a scalpel or curette, and/or removing the thickened skin using various keratolytics (salicylic acid-containing products associated with the risk of irritant effects on the normal surrounding skin). ${ }^{4-6}$

Surgery is the most invasive method and must be used when all other attempts have failed in providing relief.

\section{THE ROLE OF PEDOBAROGRAPHY}

Pedobarography (pedography) can quantify static and dynamic foot pressure, abnormal pressure across the plantar surface; any detected pedobarographic modifications must be corrected in order to relieve the pain that accompanies foot callosities, especially in the elderly.

Pedography shows the distribution of plantar pressure in the foot, it is easy to perform and specific to each individual and to each foot.7,8 Clinical examination of the patient, inspection of the footwear and plantography provide very useful information about the state of the foot and the type of load in certain phases of walking and orthostatism (Figure 2). Pedographic results enable the manufacturing of orthopedic devices to reduce symptoms and load on the feet, highly improving the quality of life of the patients.

This new approach is based on the relief of pressure or friction, removing the cause of the disease, strictly based 
on the results of pedography. Orthotic devices should be prescribed to the patient in order to redistribute mechanical pressure in the foot, allowing the lesion to heal. Clear explanations must be provided to the patients regarding the mechanisms through which the lesions are induced and the corrections that are required, because many of them search for a surgical intervention to alleviate the pain.

Silicon padding redistributes and corrects mechanical pressure, relieves the pain and represents the best conservatory measure, especially in the elderly. Specialized padding cushions protect the callus or corn and put the foot and affected toes in a position that does not permit keratotic lesions to develop (Figure $3 \mathrm{~A}, \mathrm{~B}$ ). Currently, a great variety of pads exists on the market, for example pads for hard corns, pads for soft corns, metatarsal pads, and even so-called "internal pads" (injection of liquid silicone). ${ }^{9}$ In daily dermatological practice, pads are used based on the type of keratotic disorder and the results of pedography. Toe separators prevent and reduce friction, preserve the metatarsal phalangeal joint alignment in deformations and deviations, and reduce irritation and mechanical trauma (Figure $3 \mathrm{C}$ ). They keep toes from rubbing each other and prevent the occurrence of soft corns. Interdigital pads are also used to correct digital deformity, to reduce local trauma to the skin overlying the prominent interphalangeal joints and to reduce the risk of development of interdigital heloma molle.

Custom-made padded shoe inserts (orthotics) are recommended to prevent and to treat corns or calluses in the presence of underlying foot deformity. There are different personalized types of plantar covers made accordingly to the results of pedography and with an interdisciplinary approach: dermatology, rheumatology, podiatry, surgery, and even psychology.
Dorsal bars or corrective pads correct digital deformities, reduce trauma and pain, and eliminate skin injuries (Figure $3 \mathrm{D}$ ).

\section{CONCLUSIONS}

In conclusion, protective padding of different types, recommended based on clinical examination and pedography, could be of value, particularly in the elderly, in terms of reducing plantar pressure, relieving pain and functional impairment, and avoiding surgery and hospitalization.

Prevention is also very important and can be done by wearing shoes with a large toe box and that fit well to each person. Thicker soles and all kind of protective padding relieve pressure while walking.

\section{CONFLICT OF INTEREST}

Nothing to declare.

\section{REFERENCES}

1. Höglund HC, Jeannot E, Delmi M, Chastonay P. Non traumatic lesions of the foot, calluses and nails: socioeconomic impact of an unexplored issue. Rev Med Suisse. 2011;7:2148-2152.

2. Freeman DB. Corns and Calluses Resulting from Mechanical Hyperkeratosis. Am Fam Physician. 2002;65:2277-2280.

3. Richards RN. Calluses, corns, and shoes. Semin Dermatol. 1991;10:112-114.

4. Silfverskiold JP. Common foot problems. Relieving the pain of bunions, keratoses, corns, and calluses. Postgrad Med. 1991;89:183-188.

5. Singh D, Bentley G, Trevino SG. Callosities, corns, and calluses. BMJ. 1996;312:1403-1406.

6. Gijon-Nogueron G, Garcia-Paya I, Ortega-Avila AB, Paez-Moguer J, Cervera-Marin JA. Changes in the parameters of gait after a mechanical debridement of a plantar callosities. J Tissue Viability. 2015;24:12-16.

7. Skopljak A, Muftic M, Sukalo A, Masic I, Zunic L. Pedobarography in diagnosis and clinical application. Acta Inform Med. 2014;22:374-378.

8. Panesar K. Corns and Calluses: Overview of Common Keratotic Lesions. US Pharm. 2014;39:4750.

9. Bowling FL, Metcalfe SA, Wu S, Boulton AJ, Armstrong DG. Liquid Silicone to Mitigate Plantar Pedal Pressure: A Literature Review. J Diabetes Sci Technol. 2010;4:846-852 